\title{
A comparison of three different surgery approaches and methods for neurologically intact thoracolumbar fractures: a retrospective study
}

\author{
Chao Zhu', Bin Wang ${ }^{1}$, Jian Yin ${ }^{1}$ and Xin Hui Liu ${ }^{1,2^{*}}$
}

\begin{abstract}
Objectives: The purpose of this study was to evaluate and compare the feasibility, safety, and efficacy of conventional open pedicle screw fixation (COPSF), percutaneous pedicle screw fixation (PPSF), and paraspinal posterior open approach pedicle screw fixation (POPSF) for treating neurologically intact thoracolumbar fractures.

Methods: We retrospectively reviewed 108 patients who were posteriorly stabilized without graft fusion. Among them, 36 patients underwent COPSF, 38 patients underwent PPSF, and 34 patients underwent POPSF. The clinical outcomes, relative operation indexes, and radiological findings were assessed and compared among the 3 groups.

Results: All of the patients were followed up for a mean time of 20 months. The PPSF group and POPSF group had shorter operation times, lower amounts of intraoperative blood loss, and shorter postoperative hospital stays than the COPSF group $(P<0.05)$. The radiation times and hospitalization costs were highest in the PPSF group $(P<0.05)$. Every group exhibited significant improvements in the Cobb angle (CA) and the vertebral body angle (VBA) correction (all $P<0.05$ ). The COPSF group and the POPSF group had better improvements than the PPSF group at 3 days postoperation and the POPSF group had the best improvements in the last follow-up $(P<0.05)$.

Conclusion: Both PPSF and POPSF achieved similar effects as COPSF while also resulting in lower incidences of injury. PPSF is more advantageous in the early rehabilitation time period, compared with COPSF, but POPSF is a better option when considering the long-term effects, the costs of treatment, and the radiation times.
\end{abstract}

Keywords: Pedicle screw fixation, Open, Percutaneous, Paraspinal, Thoracolumbar fracture

\section{Introduction}

Most spinal fractures occur in the thoracolumbar segment, which is biomechanically weak against external injury $[1,2]$. Although the management of thoracolumbar fractures remains controversial [3], it has been proven that surgical treatment can often achieve better clinical

\footnotetext{
* Correspondence: Ixhjnyy@163.com

'Department of Orthopedics, The Affiliated Jiangning Hospital with Nanjing Medical University, Nanjing, People's Republic of China

${ }^{2}$ Department of Orthopaedic Surgery, The Affiliated Jiangning Hospital with Nanjing Medical University, No. 169 Hushan Road, Nanjing, 211100 Jiangsu Province, People's Republic of China
}

outcomes than conservative management [4]. Shortsegment pedicle spinal instrumentation leads to the correction of kyphotic deformities, a greater initial stability, and early painless mobilization [5, 6]. However, a conventional open approach can result in some disadvantages, including blood loss, long durations of hospital stay, and injury to the paraspinal muscles $[7,8]$.

In 1968, Wiltse et al. first reported the paraspinal posterior open approach pedicle screw fixation (POPSF) method as a minimally invasive approach for treating lumbar spinal fractures [9]. Studies have proven that the

(C) The Author(s). 2021 Open Access This article is licensed under a Creative Commons Attribution 4.0 International License, which permits use, sharing, adaptation, distribution and reproduction in any medium or format, as long as you give appropriate credit to the original author(s) and the source, provide a link to the Creative Commons licence, and indicate if changes were made. The images or other third party material in this article are included in the article's Creative Commons licence, unless indicated otherwise in a credit line to the material. If material is not included in the article's Creative Commons licence and your intended use is not permitted by statutory regulation or exceeds the permitted use, you will need to obtain permission directly from the copyright holder. To view a copy of this licence, visit http://creativecommons.org/licenses/by/4.0/. The Creative Commons Public Domain Dedication waiver (http://creativecommons.org/publicdomain/zero/1.0/) applies to the data made available in this article, unless otherwise stated in a credit line to the data. 
minimally invasive approach is superior to the conventional open approach, in terms of reduced muscle injuries.

In recent years, with the rapid development of modern navigation devices, percutaneous pedicle screw fixation (PPSF) has been widely used in spinal surgery as a minimally invasive technique from the time at which it was first reported by Magerl in 1984 [10-12].

A number of clinical studies have compared PPSF to conventional open approach pedicle screw fixation (COPSF) [13-15]. Some clinical studies have also compared the paraspinal posterior open approach pedicle screw fixation (POPSF) to COPSF in the treatment of thoracolumbar fractures $[16,17]$. However, few studies have compared these three approaches/methods at the same time. In this study, we compared related data from patients with neurologically intact thoracolumbar fractures who had undergone short-segment pedicle fixation, either by the conventional posterior open approach or by the minimally invasive approach containing PPSF and POPSF. The purpose of this study was to provide a scientific basis for the suitable choice of the surgical approaches for patients with thoracolumbar fractures.

\section{Materials and methods \\ Patient samples}

We retrospectively reviewed 108 cases of singlesegment, neurologically intact thoracolumbar (T11-L2) fractures from January 2012 to August 2016. All of the patients were treated in the Orthopaedics Department of our hospital. The fracture type was classified as type A according to the new AO thoracolumbar fracture classification system [18]. All of the patients received operations within two weeks following the injury. The indications for operation were as follows: (a) type A1 and $\mathrm{CA}>15^{\circ}$, (b) dynamic fracture, and (c) kyphotic deformity getting larger after admission. These patients were divided into 3 groups based on the surgical approach and method in this study: a COPSF group (36 patients who received conventional open approach pedicle screw fixation), a PPSF group (38 patients who underwent percutaneous pedicle screw fixation), and a POPSF group (34 patients who were treated with paraspinal posterior open approach pedicle screw fixation). Before the surgery, we introduced the characteristics of three surgical approaches and methods to the patients and their family. According to patients' conditions and permissions, we performed operations by different surgical approaches and methods. All operations were performed by the same group of doctors, and the chief surgeon was the corresponding author. All of the patients received a 4-pedicle screw fixation. We did not analyze patients who received a pedicle screw in the fractured vertebra. Procedures were performed in accordance with the Declaration of Helsinki and were approved by the Ethics Committee of Human Experimentation of our hospital. The prove reg. number was 2011030. All of the patients signed corresponding informed consents before the study. The exclusion criteria were as follows: (1) pregnancy or pathologic and osteoporotic fractures, (2) younger than 18 years old or old than 60 years old, (3) an earlier surgery had been performed at the fracture site, (4) adjacent vertebral fracture, and (5) the initial fractures were combined with other diseases that could significantly influence daily life. For patients over 50 years old, we routinely measured bone mineral density to exclude osteoporosis.

\section{Reduction system}

In the COPSF group and POPSF group, the EXPEDIUM Spine System (DePuy Synthes, Raynham, MA, USA) was used; however, the VIPER MIS Spine System (DePuy Synthes, Raynham, MA, USA) was used in the PPSF group. All the pedicles in three groups were monoaxial. All the instrumentations in three groups were routinely removed 12 to 18 months after operation.

\section{Surgical procedure PPSF group}

After the general anesthesia but before the operation, the patient was place in a prone position for several minutes and the kyphosis of the injured vertebral body was partly corrected by hyperextension. We used a preoperative locator to aid in locating the pedicle projection [19]. The preoperative locator was made of stainless steel. The locator consisted of several horizontal and longitudinal rods. Different marks were made on the rods, and there were $1-\mathrm{cm}$ spaces between each horizontal rod. The patient was placed into a prone position after receiving general endotracheal anesthesia, and silicone pads were used to support the chest, abdomen, and pelvis. The preoperative locator was placed on the back of each of the patients, back with the central part (Fig. 1a). The correct pedicle projection and incision were obtained according to the different markers on the locator after observing the AP fluoroscopic image (Fig. 1b). An approximately $1.5-\mathrm{cm}$ incision was performed, and the underlying fascia was bluntly dissected. A puncture catheter was positioned on the outer and lower edges of the pedicle and was slowly advanced into the pedicle and posterior half of the vertebral body. The guide wire was then inserted into the catheter, and the needle was carefully removed (Fig. 1c, d). The fascia and soft tissue were separated by using a series of sequential dilators. A selftapping, cannulated pedicle screw with an appropriate length and diameter was inserted into the vertebra through the guide wire under the protection of the outside catheter (Fig. 1e), and then, the rod was installed 


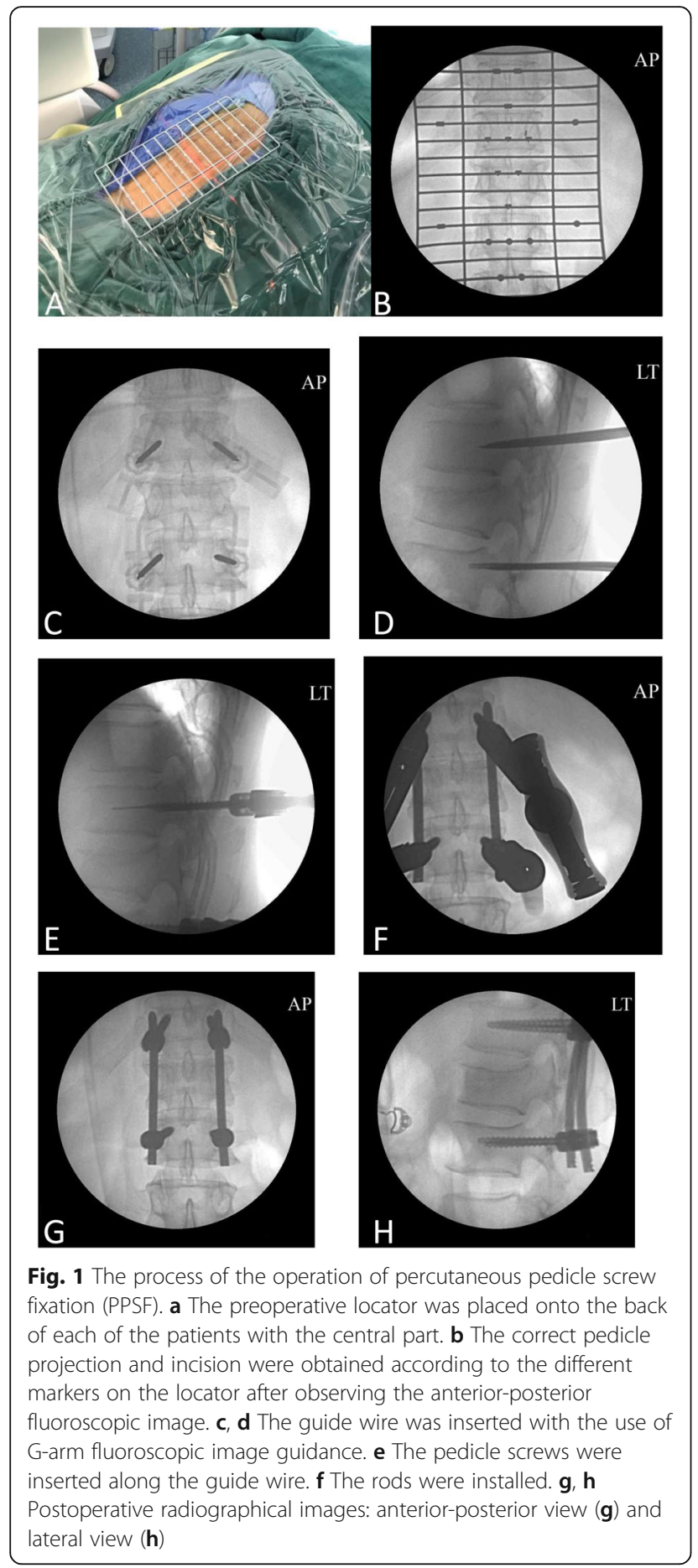

(Fig. 1f). The rods were fixed using screws. At first, we only tightened the screws at one end, and then lever of the screw towers of the other end to generate additional lordosis to correct the kyphosis. After the reduction, all the screws were tightened. During tapping, wire tapping, and screw implantation, the wire tapping and other instruments should be coaxial to the guide wire; otherwise, the guide wire may break through the anterior vertebral wall or pull out as the instrument enters and leaves. All of the procedures were performed with the use of Garm fluoroscopic image guidance.

\section{COPSF group}

The patients in the COPSF group were treated with conventional open pedicle screw fixation surgery according to the previous study [7]. The reduction technique was the same as PPSF group.

\section{POPSF group}

The positions of the fractured vertebrae were ascertained by using the G-arm. After routine sterilization and placement of the drapes, an approximate 8 - to $10-\mathrm{cm}$ midline incision was performed in the target segment. Subsequently, the thoracolumbar fascia, multifidus, and longissimus were separated in order to reach the pedicle entry point. The next procedure was the same as the traditional method (Fig. 2).

\section{Observation index}

Three groups were compared in terms of operating time, intraoperative blood loss, intraoperative fluoroscopy, hospital stay, hospitalization cost, and postoperative complications. The vertebral body angle (VBA) and Cobb's angle (CA) were evaluated at pre-operation, the third day after surgery, and the final follow-up. The VBA and $\mathrm{CA}$ were measured by conventional radiograph (Xray). The visual analog scores (VAS) was evaluated at pre-operation, the seventh day after surgery, and the final follow-up. Oswestry disability index (ODI) scores were evaluated at pre-operation and the final follow-up. Levels of serum creatine kinase (CK) were measured at pre-operation, 1 day, and 1 week after the operation.

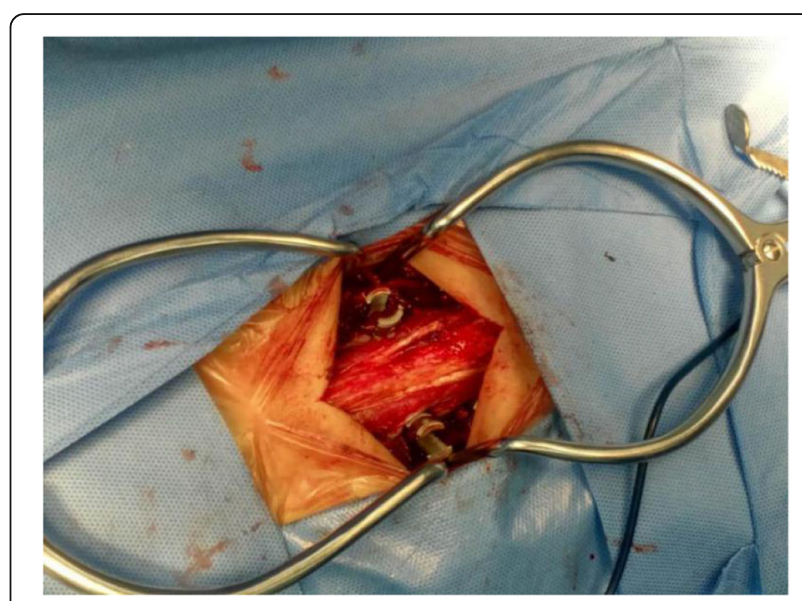

Fig. 2 The paraspinal posterior open approach pedicle screw fixation was performed. An 8- to 10-cm posterior midline incision was performed in the target segment through the interspace between the multifidus and longissimus, in order for the pedicle entry point to be exposed 


\section{Statistical analysis}

All of the statistical analyses in this study were performed by using SPSS 17.0 statistical software (IL, USA). The variables with continuous data were reported as means and standard deviations. Statistical analyses were conducted by using one-way ANOVA to compare the means if they were accord with normal distribution. Where the normal distribution was not met, the Wilcoxon rank sum test was used. The categorical variables that were demonstrated as counted data were compared by using the $\chi^{2}$ test. $P<0.05$ indicated statistical significance.

\section{Results}

The demographic and clinical characteristics of a total of 108 patients, including 68 males and 40 females (mean age 43.1 years; range 24-60 years), are shown in Table 1. Injuries were due to falling from a high height in 55 patients, traffic accidents in 30 patients, and falling from a low height in 23 patients. There were 36 patients in the COPSF group, 38 patients in the PPSF group, and 34 patients in the POPSF group. In the COPSF group, 15 for type A1, 3 for type A2, 10 for type A3, and 8 for type A4. In the PPSF group, 16 for type A1, 4 for type A2, 13 for type $\mathrm{A} 3$, and 15 for type A4. In the POPSF group, 15 for type A1, 2 for type A2, 10 for type A3, and 7 for type A4. No patient required a posterior decompression of the vertebral canal, according to CT and MRI scans. There were no significant differences in mean age, body mass index, gender, fracture level, and fracture classification among the COPSF group, the PPSF group, and the POPSF group (all $P>0.05$, Table 1). All of the patients were followed up for a mean time of 20 months (ranging from 14 to 38 months).

\section{Operation indexes}

PPSF and POPSF resulted in reduced injuries, including shorter operation times, lower amounts of intraoperative blood loss, and shorter postoperative hospital stays, compared with the COPSF (Table 2). The PPSF group had the least amounts of intraoperative blood loss $(P<0.05)$. The intraoperative radiation times and hospitalization costs were highest in the PPSF group $(P<0.05)$, but there were no significant differences between the POPSF group and the COPSF group $(P>0.05)$. There were no significant differences among the 3 groups in terms of complications, as shown in Table $3(P>0.05)$.

\section{Radiological results}

Each group exhibited significant improvements in the Cobb angle (CA) and the vertebral body angle (VBA) correction (all $P<0.05$ ). The COPSF group and the POPSF group had better improvements in both CA and VBA than the PPSF group at 3 days post-operation. No significant differences were observed between the COPSF group and the PPSF group in the last follow-up $(P>0.05)$, whereas the POPSF group had the best improvement in the last follow-up $(P<0.05)$ (Table 4$)$. In all three groups, after the materials were removed, no

Table 1 Comparison of the general data among the three groups

\begin{tabular}{|c|c|c|c|c|}
\hline Characteristics & COPSF group & PPSF group & POPSF group & $P$ value \\
\hline Cases $(n)$ & 36 & 38 & 34 & \\
\hline Mean age (years) & $46.3 \pm 7.8$ & $47.9 \pm 8.5$ & $45.6 \pm 6.8$ & $0.80^{*}$ \\
\hline \multicolumn{5}{|l|}{ Gender } \\
\hline Male & 21 & 25 & 22 & \multirow[t]{2}{*}{$0.78^{\Delta}$} \\
\hline Female & 15 & 13 & 12 & \\
\hline BMI & $22.0 \pm 2.5$ & $21.8 \pm 2.4$ & $22.1 \pm 2.6$ & $0.87^{*}$ \\
\hline \multicolumn{5}{|l|}{ Fracture level } \\
\hline $\mathrm{T} 11$ & 6 & 8 & 4 & \multirow[t]{4}{*}{$0.93^{\Delta}$} \\
\hline $\mathrm{T} 12$ & 13 & 13 & 10 & \\
\hline L1 & 11 & 12 & 13 & \\
\hline L2 & 6 & 6 & 7 & \\
\hline \multicolumn{5}{|c|}{ Fracture classification } \\
\hline $\mathrm{A} 1$ & 15 & 16 & 15 & \multirow[t]{4}{*}{$0.94^{\Delta}$} \\
\hline $\mathrm{A} 2$ & 3 & 4 & 2 & \\
\hline A3 & 10 & 13 & 10 & \\
\hline A4 & 8 & 5 & 7 & \\
\hline
\end{tabular}

COPSF conventional open approach pedicle screw fixation, PPSF percutaneous pedicle screw fixation, POPSF posterior open approach pedicle screw fixation *One-way ANOVA

${ }^{\Delta} X^{2}$ test 
Table 2 Comparison of operation indexes among the three groups

\begin{tabular}{llll}
\hline Operation indexes & COPSF group & PPSF group & POPSF group \\
\hline Operating time (min) & $125.3 \pm 23.4$ & $98.4 \pm 25.3^{\mathrm{a}}$ & $97.6 \pm 19.6^{\mathrm{b}}$ \\
Intraoperative blood loss (ml) & $367.9 \pm 37.6$ & $107.9 \pm 18.7^{\mathrm{a}}$ & $140.1 \pm 25.8^{\mathrm{b}, \mathrm{c}}$ \\
Intraoperative fluoroscopy (times) & $3.3 \pm 1.1$ & $28.4 \pm 1.4^{\mathrm{a}}$ & $3.7 \pm 1.3^{\mathrm{c}}$ \\
Hospital stay (days) & $14.4 \pm 1.8$ & $10.1 \pm 2.1^{\mathrm{a}}$ & $11.2 \pm 2.8^{\mathrm{b}}$ \\
Hospitalization cost $\left(\times 10^{3}\right.$ CNY) & $49.9 \pm 0.9$ & $55.2 \pm 1.0^{\mathrm{a}}$ & $48.6 \pm 1.3^{\mathrm{c}}$
\end{tabular}

One-way ANOVA was used to compare the operating times and the hospitalization costs. Wilcoxon rank sum tests were used to compare the intraoperative blood loss, intraoperative fluoroscopy, and hospital stays CNY China Yuan

${ }^{a}$ Significant difference between the PPSF and the COPSF groups

${ }^{b}$ Significant difference between the POPSF and the COPSF groups

'Significant difference between the POPSF and the PPSF groups

significant changes were observed about VBA and CA. There was not anterior spondylodesis performed.

\section{Effectiveness parameters}

All of the groups exhibited significant reductions from baseline in the mean visual analogue scores (VAS) after the operation. There were significant differences in the VAS at 7 days after surgery among the three groups $(P<0.05)$, and it was the lowest in the PPSF group. At the last follow up, there were no significant differences in the VAS and the Oswestry disability index (ODI) score between the PPSF group and the POPSF group. However, there were significant differences in the VAS and ODI score between these two groups and the COPSF group $(P<0.05)$, and both the VAS and ODI score were the highest in the COPSF group (Table 5).

\section{Laboratory parameters}

Creatine kinase $(\mathrm{CK})$ is released into the blood when skeletal muscle cells are damaged; thus, the content of serum CK levels can indicate the level of muscle damage [20]. All of the groups exhibited significant increases in the CK levels after the operation. There were significant differences in the CK levels at 1 day after surgery among the three groups $(P<0.05)$. The CK levels were the highest in the COPSF group and the lowest in the PPSF group. There were no significant differences in the CK levels at 7 days after surgery among the three groups $(P$ $>0.05$ ) (Table 6).

\section{Discussion}

The treatment of neurologically intact thoracolumbar fractures is still unclear [21, 22]. Conservative treatment has achieved satisfactory outcomes in several neurologically intact thoracolumbar fracture cases while avoiding surgical complications [23]. Most scholars believe that surgical treatment can not only correct kyphotic deformities, reduce pain, and allow patients to return to daily life activities at an earlier time but can also aid in avoiding the occurrence of delayed kyphosis and neurological symptoms [24, 25].

The neurologically intact thoracolumbar fractures were treated by the open posterior pedicle screw fixation method as previously described [7]. This approach has a clear exposure to the vertebrae and a shorter learning curve. However, it is also associated with higher infection rates, prolonged operation times, greater amounts of blood loss, and longer hospital stays [26].

Percutaneous pedicle screw fixation is classified as a minimally invasive surgery that does not require the need to peel the paraspinal muscles during the operation, thus reducing the chance of injury. Patients can recover more quickly after surgery [27]. In this study, operation times, amounts of blood loss, VAS scores, and hospital stays were significantly lower in the PPSF group than those in the COPSF group, which is consistent with previous studies [13-15].

Paraspinal posterior open approach pedicle screw fixation is also classified as a minimally invasive surgery. The blunt dissection from the interspace between the multifidus and longissimus can significantly reduce injury to the muscle [17]. In the POPSF group, operation

Table 3 Comparison of the postoperative complications among the three groups

\begin{tabular}{lllll}
\hline Postoperative complications & COPSF group & PPSF group & POPSF group & $P$ value* \\
\hline Incorrect screw positioning & 1 & 2 & 2 & 0.82 \\
Incision infection & 1 & 0 & 0 & 0.36 \\
Neurological symptom & 1 & 2 & 1 & 0.82 \\
\hline
\end{tabular}

${ }^{*} x^{2}$ test 
Table 4 Comparison of radiological parameters among the three groups

\begin{tabular}{llll}
\hline Radiological parameters & COPSF group & PPSF group & POPSF group \\
\hline CA $\left(^{\circ}\right)$ & & & $17.3 \pm 5.1$ \\
Preoperative & $17.4 \pm 5.4$ & $5.7 \pm 2.4^{\mathrm{a}}$ & $4.3 \pm 2.2^{\mathrm{c}}$ \\
3 d post & $4.1 \pm 1.7$ & $7.9 \pm 2.7$ & $5.9 \pm 2.9^{\mathrm{b}, \mathrm{c}}$ \\
Last & $7.6 \pm 2.8$ & & $21.9 \pm 6.1$ \\
VBA $\left(^{\circ}\right)$ & & $21.2 \pm 5.5$ & $7.2 \pm 3.3^{\mathrm{c}}$ \\
Preoperative & $20.9 \pm 5.0$ & $9.1 \pm 3.2^{\mathrm{a}}$ & $8.3 \pm 4.0^{\mathrm{c}}$ \\
3 d post & $7.0 \pm 3.0$ & $10.6 \pm 3.5$ & \\
Last & $9.3 \pm 3.2$ & & \\
\hline
\end{tabular}

$C A$ Cobb angle, VBA vertebral body angle

Using one-way ANOVA

${ }^{\text {a }}$ Significant difference between the PPSF and the COPSF groups

${ }^{b}$ Significant difference between the POPSF and the COPSF groups

'Significant difference between the POPSF and the PPSF groups

times, amounts of blood loss, VAS scores, and hospital stays were also significantly lower than those in the COPSF group. After the muscles are damaged, creatine kinase in the muscle cells is released into the blood. Therefore, the content of serum creatine kinase levels can be used as an indicator of muscle injury [28]. Our results showed that serum creatine kinase levels were significantly lower in the PPSF group and in the POPSF group than those in the COPSF group on postoperative day 1 and were the lowest amount in this group as well. VAS and hospital stays were significantly lower in the PPSF group than those in the POPSF group. These findings suggested that although both the PPSF group and the POPSF group are classified as minimally invasive approaches, percutaneous surgery is more advantageous in early recovery than paraspinal approach surgery. Our study showed that the operation time of the PPSF group was significantly higher than that of both the COPSF group and the POPSF group, and there was no significant difference between the COPSF group and the POPSF group. Similar results were observed when

Table 5 Comparison of pain assessment and function evaluation among the three groups

\begin{tabular}{llll}
\hline Clinical parameters & COPSF group & PPSF group & POPSF group \\
\hline VAS & & & \\
Preoperative & $6.8 \pm 1.3$ & $6.7 \pm 0.9$ & $7.0 \pm 1.1$ \\
7 days post & $3.3 \pm 1.1$ & $2.2 \pm 0.8^{\mathrm{a}}$ & $2.7 \pm 0.8^{\mathrm{b}, \mathrm{c}}$ \\
Last follow-up & $1.3 \pm 0.5$ & $0.7 \pm 0.5^{\mathrm{a}}$ & $0.8 \pm 0.6^{\mathrm{b}}$ \\
ODI & & & \\
Preoperative & $90.6 \pm 3.1$ & $90.3 \pm 2.5$ & $90.9 \pm 2.6$ \\
Last follow-up & $6.2 \pm 2.2$ & $3.2 \pm 2.1^{\mathrm{a}}$ & $4.1 \pm 1.9^{\mathrm{b}}$ \\
\hline
\end{tabular}

Using one-way ANOVA

VAS visual analogue scale, ODI Oswestry disability index

${ }^{a}$ Significant difference between the PPSF and the COPSF groups

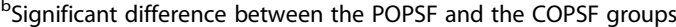

'Significant difference between the POPSF and the PPSF groups comparing G-arm exposure times. The surgeons and patients received higher doses of radiation in the PPSF group. Due to the price of the implanted device, the hospitalization costs in the PPSF group were higher than those of the COPSF and POPSF groups.

It has been reported that deviations of approximately $3 \%$ in the accuracy rates of percutaneous pedicle screw insertions are unacceptable [29]. Our accuracy results were $99.3 \%$ (143/144) in the COPSF group, 98.7\% (150/ $152)$ in the PPSF group, and $98.5 \%(134 / 136)$ in the POPSF group, and all of the complications exhibited no significant differences among the 3 groups. Although the operation of implantation of pedicle screws was not performed under direct vision, the accuracy was guaranteed, due to the use of repeated fluoroscopy during the procedure. Our results were similar to those of some other studies $[13,30]$.

Our radiological results indicated that the preoperative and postoperative Cobb's angles and VBA exhibited significant differences in all three groups. In the PPSF group, the Cobb's angles and VBA improvements were less than those in the COPSF and POPSF groups, and no difference was found between the COPSF group and the POPSF group. Several studies have reported

Table 6 Comparison of the serum creatine kinase levels among the three groups

\begin{tabular}{llll}
\hline Laboratory parameters & COPSF group & PPSF group & POPSF group \\
\hline Serum CK (U/L) & & & \\
Preoperative & $215.1 \pm 68.9$ & $223.2 \pm 55.4$ & $205.4 \pm 50.6$ \\
1 d post & $952.6 \pm 379.1$ & $484.3 \pm 234.7^{\mathrm{a}}$ & $690.0 \pm 232.9^{\mathrm{b}, \mathrm{c}}$ \\
1 week post & $185.5 \pm 59.6$ & $155.4 \pm 55.7$ & $177.5 \pm 59.1$ \\
\hline
\end{tabular}

Using one-way ANOVA

Serum $C K$ serum creatine kinase

${ }^{\text {a }}$ Significant difference between the PPSF and the COPSF groups

${ }^{\mathrm{b}}$ Significant difference between the POPSF and the COPSF groups

'Significant difference between the POPSF and the PPSF groups 
that, compared with mono-axial screws used in open surgery, percutaneous multiaxial screws are relatively weak in the bone-screw load, thus affecting the reduction effect $[12,14]$. However, as the percutaneous minimally invasive technique reduced the injury to the paraspinal muscle, the integrity of the ligamental structures was preserved; thus, the loss of the reduction was reduced $[29,31]$. There was no significant difference between the PPSF group and the COPSF group in the last follow-up, which showed that the Cobb angle correction and the VBA correction in the PPSF group were less than those in the COPSF group. The degree of paraspinal tissue injury through the use of the paraspinal posterior open approach was also lower, and the reduction loss was also lower. Our studies show that the longterm results for kyphosis correction in the POPSF group were best among the three groups.

Lee et al. [32] have shown that after lumbar muscle injury, the infiltration of adipose tissue can affect muscle contraction, thus leading to the recurrence of postoperative lower back pain (LBP). Our study showed that postoperative VAS scores were lower in the PPSF group than those in the POPSF group, but there was no difference in the long-term observation. In the final followup, VAS and ODI scores were highest in the open group, and we speculated that the recurrence of LBP in many patients of the COPSF was associated with muscle injury.

\section{Limitations}

Our study has some limitations. First, it was a singlecenter study with small sample size. Because the numbers of patients with type A2, A3, and A4 thoracolumbar fractures were very small, we could not perform further comparative among different subtypes. Second, this study was a retrospective cohort study, so the cases were easily lost to follow-up. The last, we did not use MRI and histological and electrophysiological analyses to assess multifidus muscle damages.

\section{Conclusions}

In conclusion, percutaneous pedicle screw fixation and paraspinal posterior open approach pedicle screw fixation are both acceptable, minimally invasive surgicaltherapeutic choices for patients with neurologically intact thoracolumbar fractures. These techniques have a lot of advantages over conventional open posterior pedicle screw fixations. Percutaneous screws appear to be more advantageous in early rehabilitation time periods, but paraspinal posterior open approach pedicle screw fixation is a better option, given the long-term effects, the costs of treatment, and the amount of radiation doctors and patients receive.

\section{Abbreviations}

COPSF: Conventional open pedicle screw fixation; PPSF: Percutaneous pedicle screw fixation; POPSF: Paraspinal posterior open approach pedicle screw fixation; VBA: Vertebral body angle; CA: Cobb's angle; VAS: Visual analog scores; ODI: Oswestry disability index; CK: Creatine kinase; LBP: Lower back pain

\section{Acknowledgements}

We appreciate the contribution of all patients, their families, the investigators, and the nursing staff from the Department of Orthopaedic Surgery, The Affiliated Jiangning Hospital with Nanjing Medical University.

\section{Authors' contributions}

Xinhui Liu designed the study. Xinhui Liu, Chao Zhu, Bin Wang, and Jin Yin performed all operations; Xinhui Liu was the chief surgeon. Chao Zhu and Bin Wang analyzed and interpreted the data. Chao Zhu and Jin Yin wrote the manuscript and Xinhui Liu approved the final version of the manuscript. All authors read and approved the final manuscript.

Funding

There is no funding received.

Availability of data and materials

The data and materials contributing to this article may be made available upon request by sending an e-mail to the correspondence author.

\section{Declarations}

Ethics approval and consent to participate

The ethics committee of our hospital approved this study (NO: 2011030), and all the participants had written the informed consent.

\section{Consent for publication}

Written informed consent was obtained from each patient to authorize the publication of their data.

\section{Competing interests}

The authors declare no conflict of interests.

Received: 19 March 2021 Accepted: 4 May 2021

Published online: 10 May 2021

\section{References}

1. Alpantaki K, Bano A, Pasku D, Mavrogenis AF, Papagelopoulos PJ, Sapkas GS, et al. Thoracolumbar burst fractures: a systematic review of management. Orthopedics. 2010;33(6):422-9. https://doi.org/10.3928/01477447-2010042 9-24.

2. Leucht $P$, Fischer $K$, Muhr G, Mueller EJ. Epidemiology of traumatic spine fractures. Injury. 2009;40(2):166-72. https://doi.org/10.1016/j.injury.2008.06.040.

3. Bohlman HH, Kirkpatrick JS, Delamarter RB, Leventhal M. Anterior decompression for late pain and paralysis after fractures of the thoracolumbar spine. Clin Orthop Relat Res. 1994;300:24-9.

4. Abudou M, Chen $X$, Kong $X$, Wu T. Surgical versus non-surgical treatment for thoracolumbar burst fractures without neurological deficit. Cochrane Database Syst Rev. 2013;6:CD005079. https://doi.org/10.1002/14651858. CD005079.pub3.

5. Shen WJ, Liu TJ, Shen YS. Nonoperative treatment versus posterior fixation for thoracolumbar junction burst fractures without neurologic deficit. Spine. 2001;26(9):1038-45. https://doi.org/10.1097/00007632-200105010-00010.

6. Fennell VS, Palejwala S, Skoch J, Stidd DA, Baaj AA. Freehand thoracic pedicle screw technique using a uniform entry point and sagittal trajectory for all levels: preliminary clinical experience. J Neurosurg Spine. 2014;21(5): 778-84. https://doi.org/10.3171/2014.7.SPINE1489.

7. Kim DY, Lee SH, Chung SK, Lee HY. Comparison of multifidus muscle atrophy and trunk extension muscle strength: percutaneous versus open pedicle screw fixation. Spine. 2005;30(1):123-9. https://doi.org/10.1097/01. brs.0000148999.21492.53.

8. Mobbs RJ, Sivabalan P, Li J. Technique, challenges and indications for percutaneous pedicle screw fixation. J Clin Neurosci. 2011;18(6):741-9. https://doi.org/10.1016/j.jocn.2010.09.019. 
9. Wiltse LL, Bateman JG, Hutchinson RH, Nelson WE. The paraspinal sacrospinalis-splitting approach to the lumbar spine. J Bone Joint Surg Am. 1968;50(5):919-26. https://doi.org/10.2106/00004623-196850050-00004.

10. Magerl FP. Stabilization of the lower thoracic and lumbar spine with external skeletal fixation. Clin Orthop Relat Res. 1984;189:125-41.

11. Kim BG, Dan JM, Shin DE. Treatment of thoracolumbar fracture. Asian Spine J. 2015;9(1):133-46. https://doi.org/10.4184/asj.2015.9.1.133.

12. Wang H, Zhou Y, Li C, Liu J, Xiang L. Comparison of open versus percutaneous pedicle screw fixation using the Sextant system in the treatment of traumatic thoracolumbar fractures. Clin Spine Surg. 2017;30(3): E239-E46. https://doi.org/10.1097/BSD.0000000000000135.

13. Wang B, Fan Y, Dong J, Wang H, Wang F, Liu Z, et al. A retrospective study comparing percutaneous and open pedicle screw fixation for thoracolumbar fractures with spinal injuries. Medicine. 2017;96(38):e8104. https://doi.org/10.1097/MD.0000000000008104

14. Yang M, Zhao Q, Hao D, Chang Z, Liu S, Yin X. Comparison of clinical results between novel percutaneous pedicle screw and traditional open pedicle screw fixation for thoracolumbar fractures without neurological deficit. Int Orthop. 2019;43(7):1749-54. https://doi.org/10.1007/s00264-018-4012-x.

15. Kocis J, Kelbl M, Kocis T, Navrat T. Percutaneous versus open pedicle screw fixation for treatment of type A thoracolumbar fractures. Eur J Trauma Emerg Surg. 2020;46(1):147-52. https://doi.org/10.1007/s00068-018-0998-4.

16. Fan $Y$, Zhang J, He X, Huang Y, Wu Q, Hao D. A Comparison of the miniopen Wiltse approach with pedicle screw fixation and the percutaneous pedicle screw fixation for neurologically intact thoracolumbar fractures. Med Sci Monit. 2017;23:5515-21. https://doi.org/10.12659/msm.905271.

17. Junhui L, Zhengbao P, Wenbin X, Lu H, Shengyun L, Shunwu F, et al. Comparison of pedicle fixation by the Wiltse approach and the conventional posterior open approach for thoracolumbar fractures, using MRI, histological and electrophysiological analyses of the multifidus muscle. Eur Spine J. 2017;26(5):1506-14. https://doi.org/10.1007/s00586-017-5010-1.

18. Vaccaro AR, Oner C, Kepler CK, Dvorak M, Schnake K, Bellabarba C, et al. AOSpine thoracolumbar spine injury classification system: fracture description, neurological status, and key modifiers. Spine. 2013;38(23):202837. https://doi.org/10.1097/BRS.0b013e3182a8a381.

19. Gu G, Zhang H, He S, Cai X, Gu X, Jia J, et al. Percutaneous pedicle screw placement in the lumbar spine: a comparison study between the novel guidance system and the conventional fluoroscopy method. J Spinal Disord Tech. 2015;28(9):E522-7. https://doi.org/10.1097/BSD.0b013e3182aab222.

20. Ihedioha U, Sinha S, Campbell AC. Do creatine kinase (CK) levels influence the diagnosis or outcome in patients with compartment syndrome? Scott Med J. 2005:50(4):158-9. https://doi.org/10.1177/003693300505000407.

21. Gertzbein SD. Neurologic deterioration in patients with thoracic and lumbar fractures after admission to the hospital. Spine. 1994;19(15):1723-5. https://doi.org/10.1097/00007632-199408000-00011.

22. Thomas KC, Bailey CS, Dvorak MF, Kwon B, Fisher C. Comparison of operative and nonoperative treatment for thoracolumbar burst fractures in patients without neurological deficit: a systematic review. J Neurosurg Spine. 2006;4(5):351-8. https://doi.org/10.3171/spi.2006.4.5.351.

23. Yi L, Jingping B, Gele J, Baoleri $X$, Taixiang W. Operative versus nonoperative treatment for thoracolumbar burst fractures without neurological deficit. Cochrane Database Syst Rev. 2006;:CD005079. https://doi.org/10.1 002/14651858.CD005079.pub2

24. Dai $L Y$, Jiang $S D$, Wang $X Y$, Jiang $L S$. A review of the management of thoracolumbar burst fractures. Surg Neurol. 2007;67(3):221-31; discussion 31. https://doi.org/10.1016/j.surneu.2006.08.081.

25. Gnanenthiran SR, Adie S, Harris IA. Nonoperative versus operative treatment for thoracolumbar burst fractures without neurologic deficit: a metaanalysis. Clin Orthop Relat Res. 2012;470(2):567-77. https://doi.org/10.1007/ s11999-011-2157-7.

26. Kramer M, Katzmaier P, Eisele R, Ebert V, Kinzl L, Hartwig E. Surface electromyography-verified muscular damage associated with the open dorsal approach to the lumbar spine. Eur Spine J. 2001;10(5):414-20. https://doi.org/10.1007/s005860100294.

27. Wood KB, Li W, Lebl DR, Ploumis A. Management of thoracolumbar spine fractures. Spine J. 2014;14(1):145-64. https://doi.org/10.1016/jspinee.2012.10.041.

28. Ohba T, Ebata S, Haro H. Comparison of serum markers for muscle damage, surgical blood loss, postoperative recovery, and surgical site pain after extreme lateral interbody fusion with percutaneous pedicle screws or traditional open posterior lumbar interbody fusion. BMC Musculoskelet Disord. 2017;18(1):415. https://doi.org/10.1186/s12891-017-1775-y.
29. Ringel F, Stoffel M, Stuer C, Meyer B. Minimally invasive transmuscular pedicle screw fixation of the thoracic and lumbar spine. Neurosurgery. 2006; 59(4 Suppl 2):ONS361-6; discussion ONS6-7. https://doi.org/10.1227/01.NEU. 0000223505.07815 .74

30. Kreinest M, Rillig J, Kuffer M, Grutzner PA, Tinelli M, Matschke S. Comparison of pedicle screw misplacement following open vs. percutaneous dorsal instrumentation after traumatic spinal fracture. Eur J Trauma Emerg Surg. 2019. https://doi.org/10.1007/s00068-019-01245-8.

31. Sun $X Y$, Zhang $X N$, Hai $Y$. Percutaneous versus traditional and paraspinal posterior open approaches for treatment of thoracolumbar fractures without neurologic deficit: a meta-analysis. Eur Spine J. 2017;26(5):1418-31. https://doi.org/10.1007/s00586-016-4818-4.

32. Lee JK, Jang JW, Kim TW, Kim TS, Kim SH, Moon SJ. Percutaneous shortsegment pedicle screw placement without fusion in the treatment of thoracolumbar burst fractures: is it effective?: comparative study with open short-segment pedicle screw fixation with posterolateral fusion. Acta Neurochir. 2013;155(12) discussion 12:2305-12. https://doi.org/10.1007/ s00701-013-1859-X.

\section{Publisher's Note}

Springer Nature remains neutral with regard to jurisdictional claims in published maps and institutional affiliations.

\section{Ready to submit your research? Choose BMC and benefit from:}

- fast, convenient online submission

- thorough peer review by experienced researchers in your field

- rapid publication on acceptance

- support for research data, including large and complex data types

- gold Open Access which fosters wider collaboration and increased citations

- maximum visibility for your research: over $100 \mathrm{M}$ website views per year

At BMC, research is always in progress.

Learn more biomedcentral.com/submissions 